\title{
Covid-19 Related Depression, Anxiety and Stress among Nurses Working as Front Line Workers in a Selected Hospital in Mumbai City
}

\author{
Sheryl Cornelio ${ }^{1}$, Saly Suseel ${ }^{2}$, Valsa Thomas ${ }^{3}$ \\ ${ }^{1,2,3}$ Dr. LH Hiranandani Hospital, Powai, Mumbai, Maharashtra, India \\ Corresponding Author: Sheryl Cornelio
}

\begin{abstract}
Background: Healthcare workers getting exposed to Covid-19 patients could be psychologically stressed. With the rapid spread of the disease, tremendous pressure and challenges are faced by the nurses.

Purpose: The purpose/aim of the study was to assess the level of depression, anxiety and stress among Nurses working in the Covid-19 ICU and wards and Covid-19 clinic.

Method: Quantitative approach with descriptive design was used for the study and convenient sampling was used with the sample size being 83. Standardized scale known as DASS-21 (Depression, Anxiety and stress scale) scale was used for the collection of data.

Results: To analyze the data, inferential statistics was used. The major findings of the study showed that majority of the Nurses $(34 \%)(N=28)$ had moderate anxiety. Also, majority of them $(75 \%)(N=63)$ did not find any symptoms of depression. A majority of $(48 \%)(N=40)$ had moderate level of stress.

Conclusion/Implications: The findings of the study suggest that working in the Covid-19have both negative and positive impact on the emotional impact of the Nurses. Providing required basic needs and support both physical and psychological plays a vital role in maintaining the mental health of the Nurses.
\end{abstract}

Keywords: Depression, Anxiety, Stress, Nurses, Covid-19

\section{INTRODUCTION}

As the Covid-19 pandemic accelerated, the healthcare systems worldwide have been facing tremendous impact as the pressure on the healthcare system was rising. Exploring and identifying the issues that nurses are faced by the nurses during these testing times will help to support them and strengthen protocols, improve their preparedness and comfort them. An integrative review on the physical and psychological impact will explore the issues facing by nurses during response to the Covid-19 crisis. The critical shortage of nurses, beds, and medical supplies, including PPE (personal protective equipments) are the major issues that the nurses are facing during this pandemic. Reviews reveal psychological impact and fear of COVID-19 infection among nurses.

\section{BACKGROUND}

Howard, C., (2020) in his study says that the value of the nurses is identified as this COVID-19 pandemic collapsed the value of world. Nurses are being praised for their dedication but they are in the high risk situation as lack of medical supplies especially high quality PPE which has led to even death of few nurses.

Shu, C., Yeur, H., (2020) conclude in their study that vital group among frontline health care professionals is nurses' who work across various settings such as 
tertiary hospitals, long term care agencies, schools, government healthcare agencies, nursing homes, community. Their multiple roles are vital especially in this COVID-19 pandemic.

Fawaz, M., Anshasi, H., A., Samaha, A., (2020) recommended in their study that the nurses have critical roles and responsibilities during the Covid-19 pandemic. They will continue to be at the front line of patient care in hospitals and actively involved with evaluation and monitoring. A global pandemic needs strong nursing staff engagement in clinical management, awareness and knowledge exchange, and public safety'

\section{NEED FOR THE STUDY}

El-Hage, W., Hingray,C., Lemogne, C., Yrondi, A., Brunault, P., Bienvenu, T., Etain, B., Paquet, C., Gohier, B., Bennabi, D., et al, (2020) found in their study that the healthcare workers face lot of stress which may be caused by factors such as exhaustion from personal protection equipment, concerns about rapidly changing information, inadequate access to updated information and effective communication, shortage of specific drugs, ventilators and ICU beds necessary to provide care to critically ill patients, and significant changes in their personal life, social life and family life. Nurses are more cautious about their health and having more fear and anxiety regarding transmission of infection to their family members or friends as well lack of facility to rapid test and prompt treatment. They face various challenges such as isolation, feeling of uncertainty, social stigma, workload and insecure attachment.

Shen, X., Zou, X., Zhong, X., Z., Yan, J., \& Li, L. (2020) conducted a survey on 85 ICU nurses and found various clinical manifestations mainly anorexia or indigestion (59\%), fatigue (55\%), difficulty in sleep (45\%), nervousness (28\%), frequent crying (26\%) even though suicidal thoughts (2\%). Among all young nurses (mainly fresher) are experiencing more psychological disturbances.
Abdelaziz, H., Abozeid, A., Sallam, G., S., Abboud, H, Ahmed, F. (2020) conducted a study in Egypt. The findings of the study suggested that $52.1 \%$ of the nurses who participated in the study had moderate level of total nursing stress scale. $26.2 \%$ of nurses has severe level, $13.4 \%$ of them had mild level while only 8.3 of them are at normal level. Mean $S D$ score of studied nurses regarding total nursing stress scale was $99.47 \pm 10.671$.

Khasne, R., Dhakulkar, B., Mahajan, H., Kulkarni, A. (2020) conducted the study using the tool Copenhagen burnout questionnaire. The analysis of the study revealed that the $44.6 \%$ of healthcare workers had personal burnout, 26.9\% healthcare workers had work-related burnout, while $52.8 \%$ had pandemic-related burnout. It has been found that personal and work related burnout is high among younger healthcare workers (i.e. 21-30 years) as well as in females. Pandemic related burnout is high among the doctors and the support staff.

Nurses constitute the largest workforce in a healthcare sector and their safety both physical and psychological has to be given priority.

\section{Objective}

To assess the level of Depression, Anxiety and Stress among Nurses working in the Covid-19 ICU, Wards and Covid-19 clinic.

\section{METHOD}

Quantitative Research approach was used with descriptive design. Population for the study were Nurses working in $\mathrm{Dr} \mathrm{L} \mathrm{H}$ Hiranandani Hospital. Samples selected were nurses working in Covid-19 ICU, Wards and Covid Clinic. Non probability Convenience sampling was used to select the samples with sample size being 83.Data Collection was done between October $15^{\text {th }}$ to $30^{\text {th }}$ 2020. Research Setting used was Dr L H Hiranandani Hospital, Mumbai City. Maharashtra, India. 
Sheryl Cornelio et.al. Covid-19 related depression, anxiety and stress among nurses working as front line workers in a selected hospital in Mumbai city.

\section{Tools Used}

Tool 1: Demographic tool consisting of age, area of work, Duration of exposure to Covid-19 patients

Tool 2: DASS scale: Standardized tool developed by University of New South Wales in Australia. The tool consists of 21 items in a 4-point Likert scale. The items have to be completed within 10 minutes. Each item depicts the either depression, anxiety or depression. The overall score of each category is then divided into mild, moderate and severe.

- Depression: A Score between 0-9 is Normal, 10-13 is Mild depression, 14-20 is moderate depression, 21-27 is severe depression and more than 28 is considered as Extremely severe depression.

- Anxiety: A Score between 0-9 is Normal, 8-9 is Mild Anxiety, 10-14 is moderate anxiety, $15-19$ is severe anxiety and more than 28 is considered as Extremely severe depression.

- Stress: A Score between $0-14$ is Normal, 15-18 is Mild Stress, 19-25 is moderate Stress, 26-33 is severe Stress and more than 34 is considered as Extremely severe Stress.

The overall score of each category is then divided into mild, moderate and severe.

\section{RESULTS}

\section{Section 1: Demographic Proforma:}

The analysis of the demographic proforma revealed the following results.

Table1: Demographic details of the Nurses working in Covid 19 department, $\mathrm{N}=83$

\begin{tabular}{|l|l|l|}
\hline $\begin{array}{l}\text { Demographic } \\
\text { proforma }\end{array}$ & $\begin{array}{l}\text { Total number } \\
(\mathbf{N})\end{array}$ & $\begin{array}{l}\text { Percentage } \\
(\mathbf{\%})\end{array}$ \\
\hline Age & & \\
\hline 20-25 yrs & 75 & 90.36 \\
\hline 25-30 yrs & 3 & 3.61 \\
\hline 30-35 yrs & 0 & 0 \\
\hline 35-40 yrs & 1 & 1.2 \\
\hline 40-45 yrs & 4 & 4.81 \\
\hline Area of work & & \\
\hline Ward & 35 & 42.1 \\
\hline ICU & 42 & 50.60 \\
\hline Covid Clinic & 6 & 7.23 \\
\hline Duration of exposure & & \\
\hline 0-3 months & 2 & 2.4 \\
\hline 3-6 months & 14 & 16.86 \\
\hline 6-9 months & 67 & 80.72 \\
\hline
\end{tabular}

The table 1 depicts the demographic details of the nurses in the COVID-19 department. It was found that at majority of $90.36 \%$ of the nurses were between the age group of 20-25 years having 0-4 years of clinical experience. A majority of $50.6 \%$ of the nurses were working in the COVID ICU, $42.1 \%$ of the nurses working in the Covid ward and $7.23 \%$ of the nurses from Covid clinic.

Section 2: Level of Anxiety among nurses working in Covid 19 Department

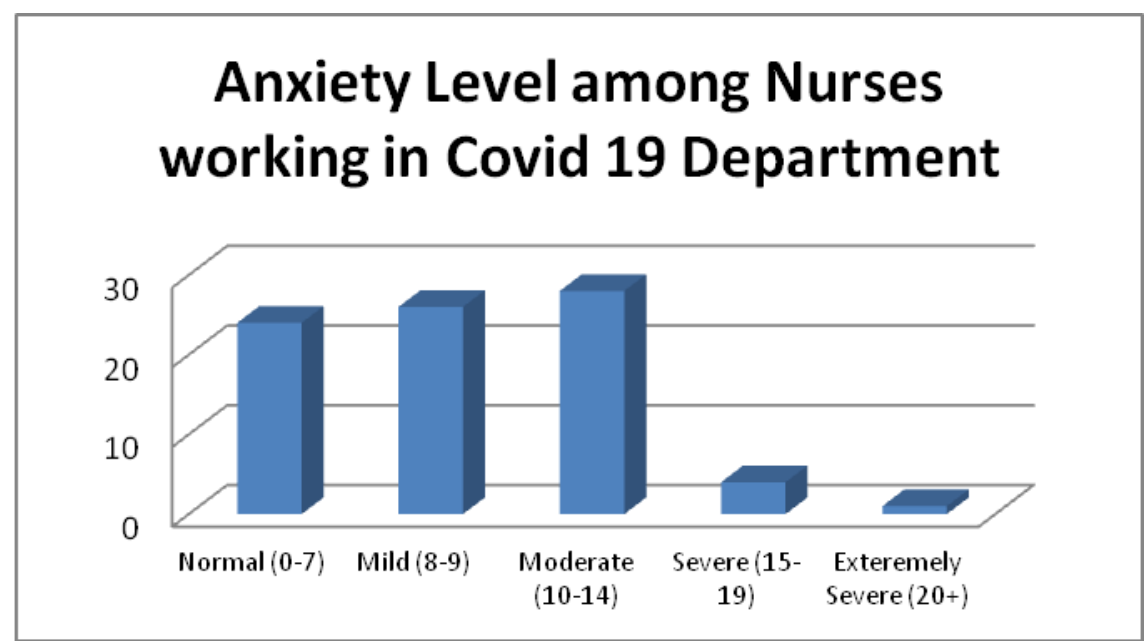

Fig 1: Graph depicting Level of anxiety among Nurses working in Covid-19 Department

The graph in Fig 1 describes the level of anxiety among the nurses working in Covid 19 department. The results showed that a majority of $34 \%(N=28)$ of the nurses 
Sheryl Cornelio et.al. Covid-19 related depression, anxiety and stress among nurses working as front line workers in a selected hospital in Mumbai city.

had moderate level of anxiety with the score ranging from 10-14. However, there was one nurse who had extremely severe level of anxiety who was moved out of the Covid department.

\section{Section 3: Level of Depression among} Nurses working in Covid-19 department

Table 2: Level of Depression among Nurses working in Covid19 department, $N=83$

\begin{tabular}{|l|l|l|}
\hline Score & $N$ & Percentage(\%) \\
\hline Normal 0-9 & 63 & 75 \\
\hline Mild 10-13 & 14 & 17 \\
\hline Moderate 14-20 & 4 & 4 \\
\hline Severe 21-27 & 2 & 4 \\
\hline Extremely Severe 28+ & 0 & 0 \\
\hline
\end{tabular}

The table 2 explains the level of depression among the nurses working in the COVID-19 department. It was found that a majority of $75 \% \quad(N=63)$ nurses did not exhibit any signs and symptoms of depression. However, a few of the nurses, $17 \%(N=14)$ exhibited mild depression who were arranged for counselling sessions with regular follow up.

\section{Section 4: level of Stress among Nurses working in Covid-19 department $N=83$}

The graph in Fig. 2 depicts the level of stress among the nurses working in the Covid 19 department. It was identified that a vast majority of the nurses i.e) $48 \%(N=48)$ worked under moderate stress level. In addition, $11 \%(N=9)$ of the nurses had severe stress and $1 \%(N=1)$ had extremely severe stress.

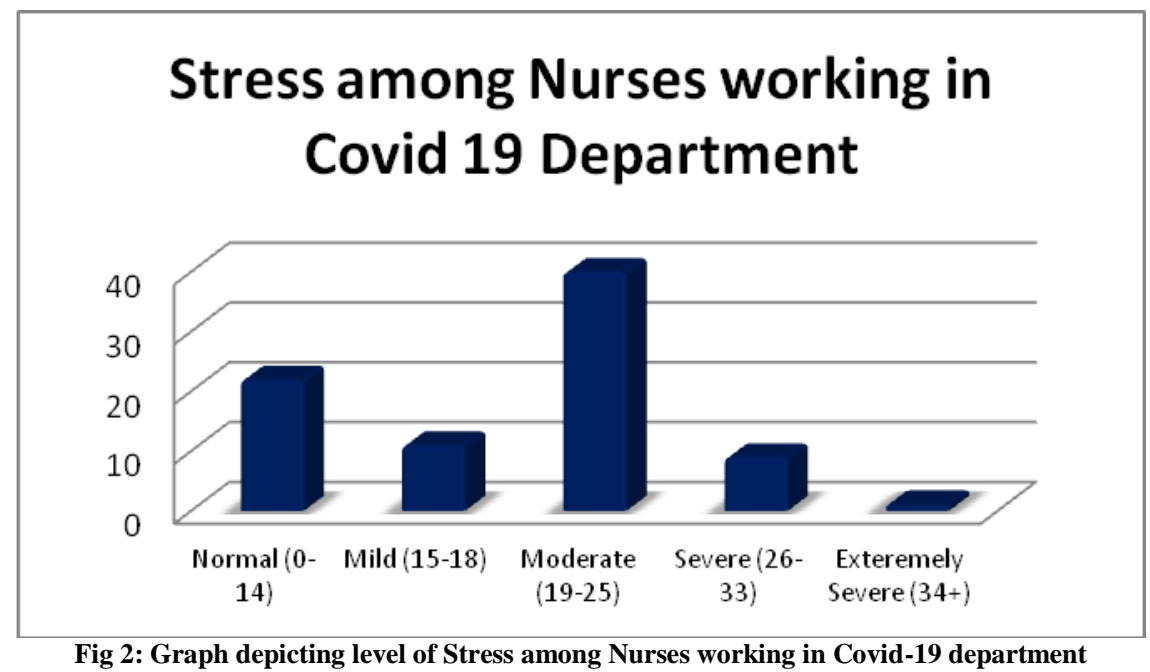

Section 5: Depression, Anxiety and stress among Nurses working in Covid 19 Department, (Fig 3), $N=83$

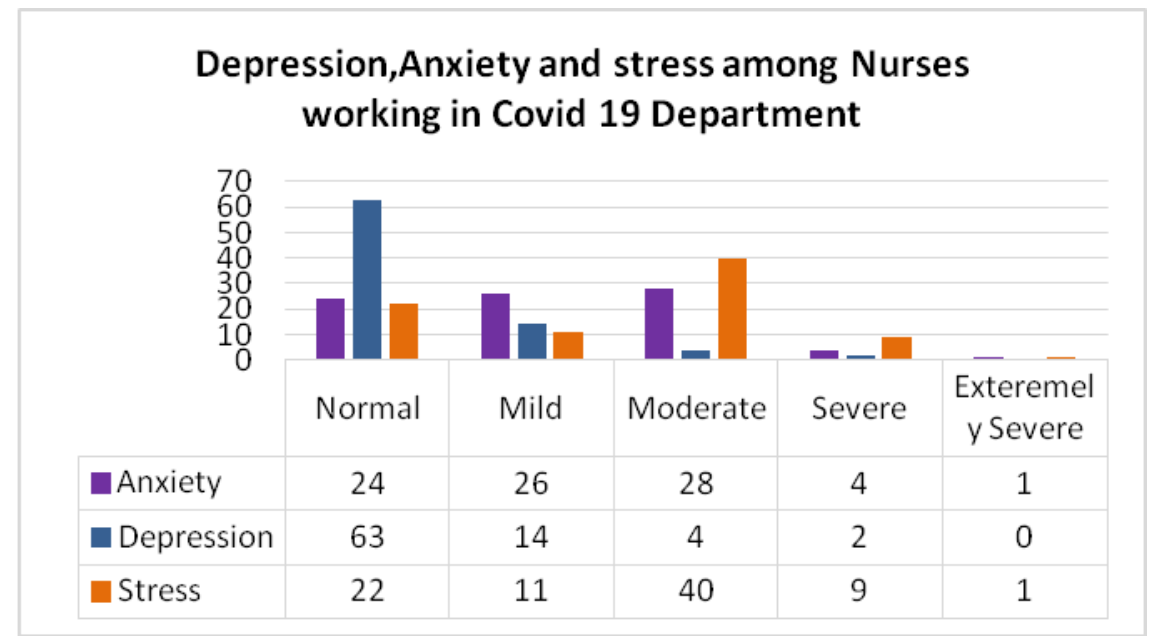

Fig 3: Depression, Anxiety and Stress among Nurses Working in Covid 19 Department 
The Fig 3 depicts the combined level of depression, anxiety and stress among the nurses working in ICU. Most of the nurses were categorized into moderate level stress and anxiety

\section{DISCUSSION}

The analysis of the data showed that the Nurses working in Covid department had moderate stress (34\%), majority of them did not have any symptoms of depression, and majority of them had moderate stress level $(48 \%)$.

Hu, D., Kong,Y., K., Li,W., Han,Q., Zang, H., Xia, L., et al. (2020) conducted a similar study in was conducted in China and was found that frontline nurses had burnout at moderate level and fear at high level. The findings revealed that majority of the nurses had moderate to high work burnout, emotional exhaustion (60.5\%), depersonalization $(42.3 \%)$, and personal accomplishment (60.6\%).

Krishna, A., Mehra, A., Niraula, A., Kafle,K.,Prasad, H. et al. (2020) conducted a study on anxiety and depression among healthcare workers in Nepal suggested that in Nepal, $38 \%$ of healthcare workers working in COVID-19 setting were suffering from anxiety and depression.

\section{CONCLUSION}

The study highlighted that Nurses who are an integral part of the COVID-19 pandemic undergo varied levels of stressors and anxiety which are attributed to various reasons. Sources of distress may include feelings self health, deadly pandemic, health of family members and friends, changes in work-style and isolation.

\section{Recommendations}

The study sets the strategic setup for the roadmap for the future. It is hence recommended from the above study the nurses like any healthcare professionals undergo lot of stress and anxiety working in Covid 19 department. Efforts should be taken towards various measures which will help reduce these by measure such as psychological counselling, relaxation measures like exercises, yoga, meditation, aerobics and incentives which will motivate them to perform better.

\section{ACKNOWLEDGMENT}

We would like to express sincere gratitude to CEO, Dr. LH Hiranandani hospital for his constant advice and untiring support in the completion of this research study. Also grateful to Capt. Valsa Thomas, Director Nursing, Dr. LH Hiranandani hospital for her encouragement and guidance.

\section{Conflict of Interest: None}

\section{Source of Funding: None}

\section{Ethical Approval: Approved}

\section{REFERENCES}

1. Abdelaziz, H., Abozeid, A., Sallam, G., S., Abboud, H, Ahmed, F. (2020). Predictive factors affecting stress among nurses providing care at COVID-19 isolation hospitals at Egypt. Nursing Open, 8(1). 498505 .

2. El-Hage, W., Hingray,C., Lemogne, C., Yrondi, A., Brunault, P., Bienvenu, T., Etain, B., Paquet, C., Gohier, B., Bennabi, D., et al, (2020). Health professionals facing the coronavirus disease 2019 (COVID-19) pandemic: What are the mental health risks? Encephale, 46(3). 7380.

3. Fawaz, M., Anshasi, H., A., Samaha, A., (2020). Nurses at the Front Line of COVID19: Roles, Responsibilities, Risks, and Rights. The American Journal of tropical medicine and Hygiene, 103(4),1341-1342

4. Howard, C., (2020). Nursing in the COVID19 pandemic and beyond: protecting, saving, supporting and honouring nurses, International Nursing Review- Nursing and Health Policy Perspective, 67(2).157-159.

5. Hu, D., Kong,Y., K., Li,W., Han,Q., Zang, H., Xia, L., et al. (2020). Frontline nurses' burnout, anxiety, depression and fear statuses and their associated factors during the COVID-19 outbreak in Wuhan, China: A large-scale cross-sectional study. E Clinical medicine, 24: 100424. 
Sheryl Cornelio et.al. Covid-19 related depression, anxiety and stress among nurses working as front line workers in a selected hospital in Mumbai city.

6. Khasne, R., Dhakulkar, B., Mahajan, H., Kulkarni, A. (2020). Burnout among Healthcare Workers during COVID-19 Pandemic in India: Results of a Questionnaire-based Survey. Indian Journal of Critical care medicine, 24(8). 664-671.

7. Krishna, A., Mehra, A., Niraula, A., Kafle,K.,Prasad, H. et al. (2020). Prevalence of anxiety and depression among healthcare workers in Nepal during Covid19pandemic. Asian Journal of psychiatry, 54: 102260

8. Shen, X., Zou, X., Zhong, X., Z., Yan, J., \& Li, L. (2020). Psychological stress of
ICU nurses in the time of COVID19.Critical Care, 24(200).

9. Shu, C., Yeur, H., (2020). Nursing Perspectives on the Impacts of COVID-19. The Journal of Nursing Research, 28(3).85.

How to cite this article: Cornelio S, Saly Suseel S, Thomas V. Covid-19 related depression, anxiety and stress among nurses working as front line workers in a selected hospital in Mumbai city. Int J Health Sci Res. 2021; 11(5): 163-168. DOI: https://doi.org/10.52403/ijhsr. 20210526 